\title{
Estimativas de parâmetros genéticos de características de crescimento em um rebanho Caracu selecionado para peso ao sobreano
}

\author{
Márcio Cinachi Pereira1 ${ }^{1}$, Maria Eugênia Zerlotti Mercadante², Lucia Galvão de Albuquerque ${ }^{3}$, \\ Alexander George Razook ${ }^{2}$, Leopoldo Andrade de Figueiredo ${ }^{2}$
}

\footnotetext{
1 Pós-graduando na Faculdade de Ciências Agrárias e Veterinárias - Unesp/Jaboticabal, SP.

${ }^{2}$ E. E. Zootecnia de Sertãozinho - IZ/APTA/SAA-SP - Caixa Postal: 63 - 14160-000 - Sertãozinho-SP.

${ }^{3}$ DZ-MGA - FCAV - Unesp. Pesquisadora do CNPq.
}

RESUMO - Foram analisados registros de 1.698 animais de um rebanho Caracu selecionado para peso pós-desmame entre os anos 1979 e 2002 com o objetivo de verificar a existência de variabilidade genética aditiva nas características de crescimento e suas interpretações. As características analisadas foram: peso ao nascer (PN), peso padronizado aos 120 dias (P120), peso ao desmame padronizado aos 210 dias (P210), peso de machos ao final da prova de ganho de peso (P378) e ganhos diários do nascimento ao desmame (GND), dos machos na prova de ganho de peso (G112), do desmame ao sobreano em machos (GDSm), peso de fêmeas padronizado aos 550 dias (P550) e ganhos das fêmeas em pastagem do desmame ao sobreano (GDSf), além da altura da garupa a um ano em machos (ALTm) e ao sobreano em fêmeas (ALTf). Os componentes de (co) variâncias, as herdabilidades e as correlações genéticas foram estimados por máxima verossimilhança restrita não-derivativa utilizando-se o software MTDFREML. As estimativas de herdabilidade e os erros-padrão foram iguais a $0,34 \pm 0,06 ; 0,11 \pm 0,05 ; 0,13 \pm 0,05$; $0,11 \pm 0,05 ; 0,35 \pm 0,09 ; 0,42 \pm 0,09 ; 0,31 \pm 0,09 ; 0,13 \pm 0,06 ; 0,21 \pm 0,08 ; 0,55 \pm 0,11 ; 0,51 \pm 0,09$ para PN, P120, P210, GND P378, P550, GDSm, GDSf, G112, ALTm e ALTf, respectivamente. As correlações genéticas entre as características foram de moderadas a altas e positivas, com exceção de algumas correlações com a característica GDSf e o PN. A seleção com base no desempenho do próprio indivíduo, como tem sido realizada, proporciona progresso genético nas características de seleção direta, assim como em algumas características com alta correlação genética.

Palavras-chave: correlação genética, gado de corte, herdabilidade

\section{Estimates of genetic parameters for growth traits of Caracu cattle selected for yearling weight}

\begin{abstract}
Records of growth traits of 1,698 animals born from 1979 to 2002 in a Caracu herd selected for yearling weight were used to estimate genetic parameters for birth weight (PN), weight at 4 months adjusted at 120 days (P120), weaning weight adjusted at 210 days (P210), daily weight gain from birth to weaning (GND), weight adjusted at 378 days of males (P378), weight adjusted at 550 days of heifers (P550), daily weight gain during the performance test (G112), postweaning daily weight gain of males (GDSm), post-weaning daily weight gain of heifers (GDSf), hip height of males (ALTm) and hip height of heifers (ALTf). Components of covariance were estimated by multiple trait derivative free maximum likelihood, using the software MTDFREML. Heritability and standard errors for PN, P120, P210, GND, P378, P550, GDSm, GDSf, G112, ALTm and ALTf were respectively $0.34 \pm 0.06,0.11 \pm 0.05,0.13 \pm 0.05,0.11 \pm 0.05,0.35 \pm 0.09 ; 0.42 \pm 0.09$ $0.31 \pm 0.09 ; 0.13 \pm 0.06 ; 0.21 \pm 0.08 ; 0.55 \pm 0.11$ and $0.51 \pm 0.09$. Except for some estimates for GDSf and PN, genetic correlations between traits were moderate to high and the positive. Genetic gains on growth traits are expected by direct selection on individual performance.
\end{abstract}

Key Words: beef cattle, genetic correlation, heritability

\section{Introdução}

As raças de bovinos de origem européia adaptadas aos trópicos, como a Caracu, podem contribuir significativamente para melhorar a eficiência e o desenvolvimento da pecuária de corte no Brasil, uma vez que estão presentes no país desde o século XVI. Estes animais sofreram rigorosa seleção natural e suportam servir em monta natural em climas em que animais de origem européia não teriam a mesma habilidade, como no Brasil Central.

Com o crescente desenvolvimento tecnológico e o aumento da produção pecuária brasileira, os criadores têm buscado novas técnicas para melhorar seus plantéis. A aplicação de diferentes metodologias tem possibilitado a 
técnicos e criadores identificar animais superiores para serem pais das futuras gerações. Entre essas metodologias, uma das mais importantes e mais utilizadas é o BLUP (Best Linear Unbiased Prediction), que permite o uso de todas as informações disponíveis pela incorporação da matriz de relações genético-aditivas, fazendo com que todas as covariâncias sejam consideradas entre indivíduos de uma mesma geração ou de gerações diferentes (Sorensen \& Kennedy, 1986).

A estimação de parâmetros genéticos em programas de melhoramento é de grande relevância, haja vista as mudanças ocorridas na população, uma vez que estes parâmetros são utilizados nas predições de valores genéticos e na predição da resposta à seleção. Boas revisões de parâmetros genéticos de várias características de importância econômica são encontradas na literatura (Koots et al., 1994; Mercadante et al., 1995; Lôbo et al., 2000, entre outras), entretanto, estas publicações evidenciam a ausência de informações sobre estimativas de parâmetros genéticos obtidas em populações de Bos taurus taurus adaptadas aos trópicos explorados exclusivamente para produção de carne, como é o caso da raça Caracu, e a pequena quantidade de estudos sobre parâmetros genéticos de características relacionadas ao tamanho do animal, como altura e suas relações com peso. Os estudos com a raça Caracu são referentes a rebanhos explorados para a produção de leite (Queiroz et al., 2005).

O objetivo neste estudo foi verificar a variabilidade genética, por meio da estimação de componentes de (co) variâncias genéticas e de ambiente, herdabilidades e correlações nas características de crescimento de um rebanho Caracu durante os 24 anos de seleção para peso ao sobreano.

\section{Material e Métodos}

Foram utilizados dados do rebanho Caracu da Estação Experimental de Zootecnia de Sertãozinho, que faz parte do Projeto de Seleção das Raças Zebuínas e Caracu, iniciado em 1976 e com as primeiras progênies nascidas em 1978. O processo seletivo segue os mesmos procedimentos aplicados às demais raças (Nelore, Guzerá e Gir) pertencentes à Estação Experimental de Sertãozinho. Os detalhes deste processo foram descritos por Razook et al. $(1993,1998)$ e Mercadante et al. (2003).

Os animais (machos e fêmeas) foram criados em pastagem até o desmame, que ocorre por volta dos 7 meses, quando os machos foram encaminhados para a prova de ganho de peso, onde permaneceram 168 dias. As fêmeas permaneceram em pastagem até os 18 meses de idade. Os machos foram selecionados com base no maior diferencial de seleção em função da média dos contemporâneos para peso ao final da prova, padronizado para 378 dias (P378). As fêmeas foram selecionadas ao sobreano, com base no maior diferencial de seleção para peso padronizado aos 550 dias (P550). Anualmente, foram selecionados, em média, três machos e 20 fêmeas.

Foram analisados dados relativos às progênies nascidas entre os anos de 1979 e 2002, compondo um banco de dados de 1.698 animais, filhos de 71 touros e 498 matrizes.

As características estudadas foram: peso ao nascer (PN), peso padronizado aos 120 dias (P120), peso ao desmame padronizado aos 210 dias (P210), peso de machos ao final da prova de ganho de peso (P378), peso de fêmeas padronizado aos 550 dias (P550), ganhos médios diários dos machos na prova (G112), do nascimento ao desmame (GND), do desmame ao sobreano em machos (GDSm) e do desmame ao sobreano em fêmeas (GDSf), além da altura da garupa a um ano de idade em machos (ALTm) e ao sobreano em fêmeas (ALTf).

$\mathrm{Na}$ consistência dos dados, foram eliminados os registros de animais guaxos, animais sem pais conhecidos e aqueles com medidas fora da amplitude de $\pm 3,50$ desviospadrão em relação à média do grupo contemporâneo. Após a consistência, foram obtidos o número de observações, as médias, os desvios-padrão e os coeficientes de variação das características estudadas, representados na Tabela 1.

Com o objetivo de verificar a estrutura familiar existente nessa população, foi realizado um programa no SAS (2000) obtendo-se o número médio de filhos (as) e netos (as) por touro e vaca.

Os componentes de (co) variâncias, herdabilidades e as correlações genéticas foram estimados por máxima verossimilhança restrita não-derivativa, utilizando-se o software MTDFREML (Multiple Trait Derivative Free Maximum Likelihood), descrito por Boldman et al. (1995). Todas as características foram analisadas aplicando-se um modelo animal incorporando matriz de parentesco. Para montar o arquivo de pedigree e, conseqüentemente, melhorar as relações de parentesco, foi elaborado um programa no SAS (2000) para retroceder as gerações até que não fosse incorporado nenhum animal. Foram retrocedidas seis gerações, perfazendo um total de 2.405 animais no pedigree.

No MTDFREML, é utilizado um algoritmo simplex para obtenção do mínimo de $-2 \log \mathrm{L}$ (em que $\mathrm{L}=$ função de verossimilhança) em modelos com múltiplos parâmetros. Os valores dos componentes de (co) variância que minimizam a função $-2 \log L$ são as estimativas de máxima verossimilhança desses componentes. O critério de convergência usado foi de $10^{-9}$, repetindo-se as análises o 
Tabela 1 - Número de indivíduos (n), média, desvio-padrão e coeficiente de variação (CV) para as características estudadas Table 1 - Number of individuals (n), mean, standard deviation and coefficient of variation (CV) for the studied traits

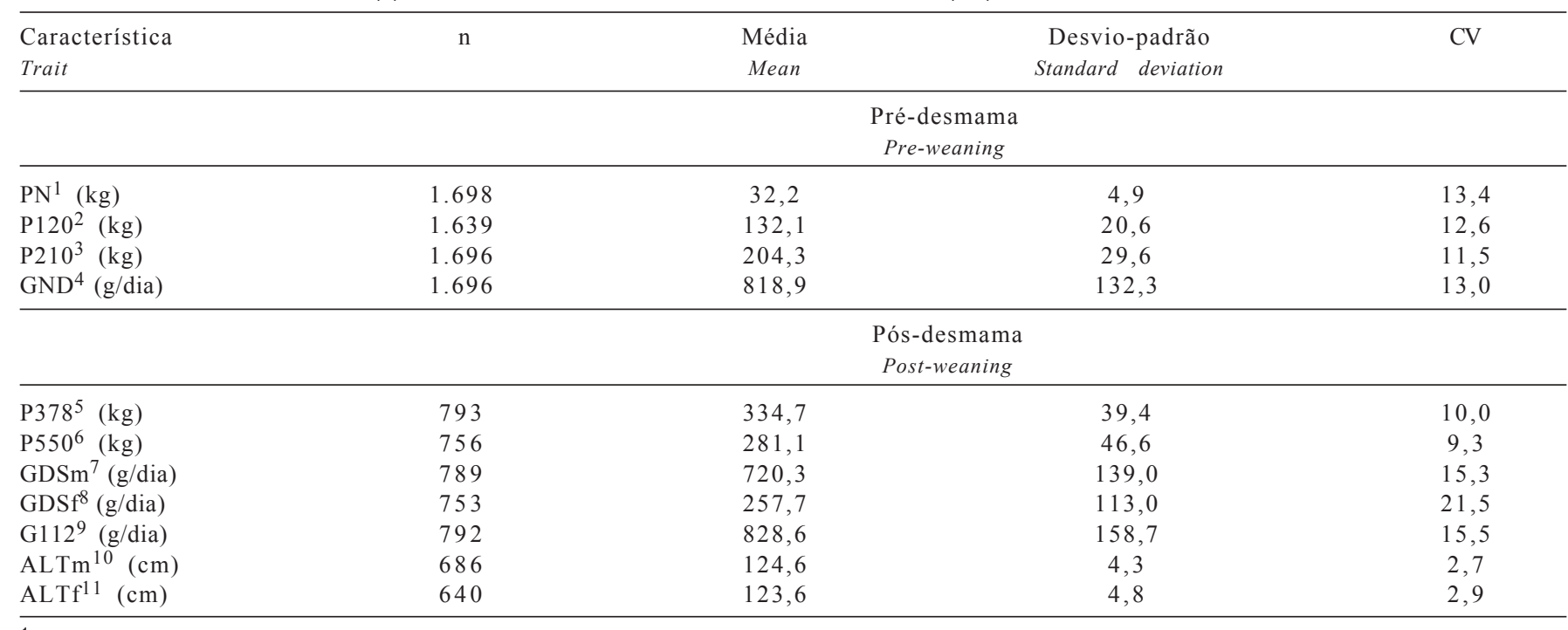

\footnotetext{
1 Peso ao nascer (birth weight).

2 Peso padronizado aos 120 dias (weight adjusted to 120 days).

3 Peso ao desmame padronizado aos 210 dias (weaning weight adjusted to 210 days).

4 Ganho médio diário do nascimento ao desmame (daily weight gain from birth to weaning).

5 Peso de machos ao final da prova de ganho de peso (weight of males adjusted to 378 days)

6 Peso de fêmeas padronizado aos 550 dias (weight of heifers adjusted to 550 days).

7 Ganho médio diário da desmame ao sobreano em machos (average post-weaning daily gain of males).

8 Ganho médio diário da desmame ao sobreano em fêmeas (average post-weaning daily gain of heifers).

9 Ganho médio diário na prova (average daily gain during the performance test).

10 Altura da garupa em machos (hip height of males).

${ }^{11}$ Altura da garupa em fêmeas (hip height of heifers).
}

quanto necessário para que a diferença entre as estimativas permanecesse menor que $10^{-9}$, sempre utilizando os valores das análises anteriores.

No modelo de análise, considerou-se como efeito fixo o grupo contemporâneo definido como sexo, mês e ano de nascimento para características tomadas até o desmame. Neste período, animais de ambos os sexos permaneceram no mesmo ambiente, em regime de pastagem até os 7 meses de idade. Para as características pós-desmama, o grupo contemporâneo foi definido como mês e ano de nascimento e as características de machos e fêmeas foram consideradas características distintas.

Primeiramente, foram realizadas análises uni-características para todas as características estudadas, aplicando-se diferentes modelos que diferiram quanto aos efeitos aleatórios, desde o mais completo (efeitos genéticos direto e materno e efeito de ambiente permanente materno) até o reduzido (efeito genético direto). Para verificar a significância dos efeitos aleatórios incluídos no modelo e definir os modelos mais adequados para as análises bicaracterísticas, foi utilizado o teste de razão de verossimilhança (LRT), que verifica a diminuição do valor de -2 Log L pela inclusão de mais um parâmetro no modelo, a qual segue distribuição de qui-quadrado com $g$ graus de liberdade, em que $g$ é a diferença em números de parâmetros estimados entre os dois modelos comparados (Dobson, 1990). Neste teste, a probabilidade de erro utilizada foi de $5 \%$.

O modelo geral utilizado foi:

$$
y=X \beta+Z_{a} a+Z_{m} m+Z_{c} c+e
$$

em que $\mathrm{y}=$ vetor das características observadas; $\beta=$ vetor de efeitos fixos; $a=$ vetor de efeitos genéticos aditivos diretos; $\mathrm{m}=$ vetor de efeitos genéticos aditivos maternos; $\mathrm{c}=$ vetor de efeitos de ambiente permanente materno; e $\mathrm{e}=$ vetor de efeitos residuais. $X, Z_{a}, Z_{m}$ e $Z_{c}$ são matrizes de incidência relacionando $\beta$, a, m e c a y. Neste etudo, assumiu-se que $\mathrm{E}[\mathrm{y}]=\mathrm{X} \beta ; \operatorname{Var}(\mathbf{a})=\mathbf{A} \otimes \sum_{\mathrm{a}} ; \operatorname{Var}(\mathbf{m})=\mathbf{A} \otimes \sum_{\mathrm{m}}$, $\operatorname{Var}(\mathbf{c})=\mathbf{I} \otimes \sum_{\mathrm{c}}$ e $\operatorname{Var}(\mathbf{e})=\mathbf{I} \otimes \sum_{\mathrm{e}}$, em que $\sum_{\mathrm{a}}$ é a matriz de covariâncias genéticas aditivas; $\Sigma_{\mathrm{m}}$, a matriz de covariâncias genéticas maternas; $\Sigma_{\mathrm{c}}$, a matriz de covariâncias de ambiente permanente materno; $\Sigma_{\mathrm{e}}$, a matriz de covariância residual; A, a matriz do numerador de relações genéticoaditivas; I, a matriz identidade; $\mathrm{e} \otimes$, o produto direto entre matrizes. Assumiu-se ainda que os vetores a, m, c e e são não corrrelacionados entre si.

As (co)variâncias e os parâmetros genéticos foram estimados separadamente para os períodos pré e pósdesmama, em análises uni e bi características, respectiva- 
mente. Uma vez que, após o desmame, as características foram medidas em apenas um dos sexos, em machos ou em fêmeas, foram realizadas análises bi-características utilizando-se o peso à desmama como segunda característica, de forma a incorporar informações de todos os animais. Nestas últimas análises, a covariância ambiental foi considerada nula, tendo-se em vista a permanência dos animais em ambientes distintos.

Para as características pré-desmama, o melhor ajuste indicado pelo teste da razão de verossimilhança foi obtido com o modelo completo que incluiu o efeito genético aditivo direto do animal, o efeito genético materno e o efeito de ambiente permanente comum aos filhos de mesma mãe. Para as características pós-desmama, no entanto, utilizando-se o mesmo teste, o melhor ajuste foi obtido com o modelo contendo apenas o efeito genético direto do animal. Para a obtenção das correlações genéticas, o modelo utilizado foi aquele que melhor se ajustou a cada característica.

\section{Resultados e Discussão}

As estimativas dos parâmetros genéticos estão sumarizadas na Tabela 2. Para as características pré-desmama, os dados analisados incluíram, em média, vacas com 2,92 filhos, touros com 11,89 filhas e 38,28 netos(as). Este tipo de estrutura familiar é muito importante para a partição dos efeitos genéticos direto e materno e do efeito de ambiente permanente materno.

As estimativas de herdabilidade para os efeitos genéticos diretos $\left(\mathrm{h}_{\mathrm{d}}{ }^{2}\right)$ foram baixas, com exceção do PN. Além disso, para as características P120, P210 e GND, as estimativas das $\mathrm{h}_{\mathrm{d}}^{2}$ foram muito próximas, indicando que a utilização das características P120, P210 ou GND como critério de seleção em um programa de melhoramento trará progresso genético lento, uma vez que sofrem grande influência do ambiente materno, comprovado pelos altos valores da por- ção da variância de ambiente permanente $\left(\mathrm{c}^{2}\right)$, comparativamente à porção da variância genética direta e da genética materna. Estes valores revelam também a importância da inclusão do efeito de ambiente materno no modelo de análise dessas características, evitando superestimação do efeito genético aditivo direto e/ou do efeito genético materno. As estimativas de herdabilidade para os efeitos genéticos materno $\left(\mathrm{h}_{\mathrm{m}}{ }^{2}\right)$ foram de magnitude baixa com erros-padrão elevados, o que pode indicar estimativas pouco confiáveis.

Os valores estimados de $\mathrm{h}_{\mathrm{d}}{ }^{2} \mathrm{e} \mathrm{h}_{\mathrm{m}}{ }^{2}$ para $\mathrm{PN}$ foram os mais elevados e estão próximos dos encontrados na maioria dos resultados da literatura. Porém, a estimativa $\mathrm{de}_{\mathrm{m}}{ }^{2}$ foi inferior a $\mathrm{h}_{\mathrm{d}}{ }^{2}$, o que também é coerente com outros estudos (Siqueira et al., 2003; Mello et al., 2002). Coeficientes de herdabilidades diretas, variando de 0,14 a 0,36 , e maternas semelhantes aos descritos neste trabalho foram estimados para a característica peso ao nascer por Euclides Filho et al. (1978), Eler et al. (1995) e Scarpati \& Lôbo (1999), para a raça Nelore; Marques et al. (1999), para a raça Simental; Ferreira et al. (1999), para a raça Hereford; e Mascioli et al. (1996), para a raça Canchim.

Para o P120, estimativa de $\mathrm{h}_{\mathrm{d}}{ }^{2}$ próxima foi relatada por Karsburg (2003), em bovinos da raça Santa Gertrudes. Estimativa menor foi relatada por Ribeiro et al. (2000), também em bovinos Santa Gertrudes, enquanto estimativa superior $(0,29)$ foi relatada por Siqueira et al. (2003), em bovinos Nelore. Essa característica pode expressar a habilidade das matrizes em criar suas progênies e pode ser utilizada em programas de seleção nos quais se deseja melhorar esta característica, porém com modesto progresso genético.

Quanto a P210, Mercadante et al. (1998), analisando este mesmo rebanho com número menor de anos, encontraram $\mathrm{h}_{\mathrm{d}}{ }^{2}$ exatamente igual ao utilizarem modelo semelhante. Estimativas também próximas à deste trabalho foram relatadas por Eler et al. (1995) e Albuquerque \& Meyer (2001), variando de 0,13 a 0,16 , na raça Nelore. Entretanto, valores

Tabela 2 - Estimativas de variâncias genética aditiva direta $\left(\sigma_{\mathrm{a}}{ }^{2}\right)$ e materna $\left(\sigma_{\mathrm{m}}{ }^{2}\right)$, de ambiente permanente materno $\left(\sigma_{\mathrm{c}}{ }^{2}\right)$ e residual $\left(\sigma_{\mathrm{e}}{ }^{2}\right)$, herdabilidades direta $\left(\mathrm{h}_{\mathrm{d}}^{2}\right)$ e materna $\left(\mathrm{h}_{\mathrm{m}}{ }^{2}\right)$ e variância do ambiente permanente materno como proporção da variância fenotípica $\left(\mathrm{c}^{2}\right)$ para as características pré desmama

Table 2 - Estimates of direct $\left(\sigma_{a}^{2}\right)$ and maternal $\left(\sigma_{m}^{2}\right)$ additive genetic, maternal permanent environment $\left(\sigma_{c}^{2}\right)$ and residual $\left(\sigma_{e}^{2}\right)$ variances, direct $\left(h_{d}^{2}\right)$ and maternal $\left(h_{m}{ }^{2}\right)$ heritabilities and maternal permanent environment effect as a proportion of the phenotypic variance $\left(c^{2}\right)$ for pre-weaning traits

\begin{tabular}{|c|c|c|c|c|c|c|c|}
\hline $\begin{array}{l}\text { Característica } \\
\text { Trait }\end{array}$ & $\sigma_{\mathrm{a}}^{2}$ & $\sigma_{\mathrm{m}}^{2}$ & $\sigma_{\mathrm{c}}^{2}$ & $\sigma_{\mathrm{e}}^{2}$ & $\mathrm{~h}_{\mathrm{d}}^{2}$ & $\mathrm{~h}_{\mathrm{m}}^{2}$ & $c^{2}$ \\
\hline $\mathrm{PN}^{1}(\mathrm{~kg})$ & 6,63 & 1,86 & 0,85 & 10,28 & $0,34 \pm 0,06$ & $0,09 \pm 0,04$ & $0,04 \pm 0,03$ \\
\hline $\mathrm{P} 120^{2}(\mathrm{~kg})$ & 30,85 & 14,07 & 48,09 & 193,50 & $0,11 \pm 0,05$ & $0,05 \pm 0,04$ & $0,17 \pm 0,04$ \\
\hline $\mathrm{P} 210^{3}(\mathrm{~kg})$ & 75,29 & 12,25 & 90,61 & 387,43 & $0,13 \pm 0,05$ & $0,02 \pm 0,03$ & $0,16 \pm 0,04$ \\
\hline $\mathrm{GND}^{4}$ (g/dia, g/day) & $1.276,14$ & 91,00 & $2.223,81$ & $8.090,47$ & $0,11 \pm 0,05$ & $0,01 \pm 0,03$ & $0,19 \pm 0,04$ \\
\hline
\end{tabular}

\footnotetext{
1 Peso ao nascer (birth weight).

2 Peso padronizado aos 120 dias (weight adjusted to 120 days)

3 Peso ao desmame padronizado aos 210 dias (weaning weight adjusted to 210 days).

4 Ganho médio diário do nascimento ao desmame (average daily gain from birth to weaning)
} 
mais altos $(0,37$ e 0,23 , respectivamente) foram encontrados por Mascioli et al. (1997), em animais Canchim, e Knackfuss et al. (2006), em animais Gir.

Knackfuss et al. (2006) e Eler et al. (2001) relataram para GND estimativas de $\mathrm{h}_{\mathrm{d}}^{2}$ maiores, de 0,22 e 0,28 , respectivamente, em rebanhos Gir e Nelore.

As estimativas dos parâmetros genéticos para as características pós-desmama estão sumarizadas na Tabela 3 .

As estimativas das variâncias fenotípicas das características P378, GDSm e G1 12 foram superiores em relação às variâncias das características P550 e GDSf. Essa superioridade é explicada pelo fato de que as medidas P378, GDSm e G112 são tomadas em animais machos em confinamento, diferentemente das características P550 e GDSf, tomadas em fêmeas em pastagem. Entretanto, as variâncias fenotípicas das alturas de machos e fêmeas foram próximas.

Em geral, as estimativas de herdabilidade para o efeito genético direto para todas as características pós-desmama foram de magnitudes medianas a altas, indicando que a variação genética aditiva contribuiu com grande parte da variação total e que estas características podem responder muito bem à seleção individual.

A estimativa da herdabilidade para o $\mathrm{P} 378$ foi próxima à encontrada por Mercadante et al. (1995), em revisão de parâmetros genéticos estimados em rebanhos zebuínos. Knackfuss et al. (2006), em estudo mais recente, obtiveram $\mathrm{h}_{\mathrm{d}}{ }^{2}$ de 0,45 para a mesma característica em um rebanho Gir também selecionado para peso ao sobreano.

Para P550, a estimativa da $\mathrm{h}_{\mathrm{d}}{ }^{2}$ foi igual a 0,42 , inferior à encontrada por Mercadante et al. (1998), de 0,54, e superior à obtida por Mercadante et al. (2003), para animais da raça Nelore (0,37), e Knackfuss et al. (2006), que obtiveram estimativa igual a 0,29 .
Os valores das estimativas de $\mathrm{h}_{\mathrm{d}}{ }^{2}$ para as características de seleção direta (P378 e P550) aplicadas neste rebanho durante 23 anos indicam que diferenças genéticas entre os indivíduos são responsáveis, em grande parte, pela variação nas características e que o fenótipo constitui indicação segura do genótipo do animal. Assim, a seleção durante os 23 anos, baseada no desempenho do próprio indivíduo, deve ter proporcionado progresso genético significativo nessas características.

As características GDSm e G112 apresentaram maior coeficiente de herdabilidade se comparadas à característica GDSf. Essa diferença era esperada, visto que GDSm e G112 são medidas tomadas apenas nos machos durante confinamento na prova de ganho de peso, enquanto GDSf é tomada somente em fêmeas sob regime de pastagem. Portanto, o melhor controle ambiental proporcionado pela prova de ganho de peso, por si só, pode explicar grande parte das diferenças nos valores das estimativas das herdabilidade.

A inversão observada nos valores das estimativas de herdabilidade das características P378, P550, GDSm e GDSf podem ser explicadas pelos altos valores dos erros-padrão, que, se considerados, tornam essas estimativas de herdabilidade muito próximas.

As estimativas de herdabilidade para altura da garupa foram altas tanto para os machos quanto para as fêmeas, concordando com as estimativas obtidas em bovinos de origem européia. Para altura a um ano de idade, Bourdon \& Brinks (1986), estudando animais da raça Hereford, encontraram herdabilidade igual à estimada neste trabalho. Kriese et al. (1991), em rebanhos da raça Hereford e Brangus, relataram herdabilidades iguais a 0,66 e 0,27 para altura a um ano de idade, respectivamente. Para altura ao sobreano, as estimativas de herdabilidades variaram de 0,54 a 0,94 nas

Tabela 3 - Estimativas de variâncias genética aditiva direta $\left(\sigma_{\mathrm{a}}{ }^{2}\right)$, residual $\left(\sigma_{\mathrm{e}}{ }^{2}\right)$ e fenotípica $\left(\sigma_{\mathrm{P}}{ }^{2}\right)$ e herdabilidade direta $\left(\mathrm{h}_{\mathrm{d}}{ }^{2}\right)$ para as características pós-desmama

Table 3 - Estimates of direct additive genetic $\left(\sigma_{a}{ }^{2}\right)$, residual $\left(\sigma_{e}{ }^{2}\right)$ and phenotypic $\left(\sigma_{P}{ }^{2}\right)$ variances and direct heritability $\left(h_{d}{ }^{2}\right)$ for post-weaning traits

\begin{tabular}{|c|c|c|c|c|}
\hline $\begin{array}{l}\text { Característica } \\
\text { Trait }\end{array}$ & $\sigma_{\mathrm{a}}^{2}$ & $\sigma_{\mathrm{e}}^{2}$ & $\sigma_{\mathrm{P}}^{2}$ & $\mathrm{~h}_{\mathrm{d}}{ }^{2}$ \\
\hline P378 ${ }^{1}(\mathrm{~kg})$ machos (males) & 422,43 & 777,51 & $1.199,94$ & $0,35 \pm 0,09$ \\
\hline $\mathrm{P} 550^{2}$ (kg) fêmeas (heifers) & 312,77 & 428,59 & 741,36 & $0,42 \pm 0,09$ \\
\hline $\mathrm{GDSm}^{3}(\mathrm{~g} / \mathrm{dia}, \mathrm{g} / d a y)$ & $3.964,74$ & $8.710,80$ & $12.675,54$ & $0,31 \pm 0,09$ \\
\hline $\operatorname{GDSf}^{4}(\mathrm{~g} / \mathrm{dia}, \mathrm{g} /$ day $)$ & 415,26 & $2.700,55$ & $3.115,82$ & $0,13 \pm 0,06$ \\
\hline G1125 (g/dia, g/day $)$ & $3.595,99$ & $2.703,32$ & $5.845,25$ & $0,21 \pm 0,08$ \\
\hline $\operatorname{ALTm}^{6}(\mathrm{~cm})$ & 7,07 & 5,83 & 12,95 & $0,55 \pm 0,11$ \\
\hline $\operatorname{ALTf}^{7}(\mathrm{~cm})$ & 7,11 & 6,75 & 13,86 & $0,51 \pm 0,09$ \\
\hline
\end{tabular}

\footnotetext{
1 Peso de machos ao final da prova de ganho de peso (weight of males adjusted to 378 days).

2 Peso de fêmeas padronizado aos 550 dias (weight of heifers adjusted to 550 days).

3 Ganho médio diário da desmame ao sobreano em machos (average post-weaning daily gain of males).

${ }^{4}$ Ganho médio diário da desmame ao sobreano em fêmeas (average post-weaning daily gain of heifers).

5 Ganho médio diário na prova (average daily gain during the performance test).

${ }^{6}$ Altura da garupa em machos (hip height of males).

${ }^{7}$ Altura da garupa em fêmeas (hip height of heifers).
} 
diferentes raças analisadas (Nevile et al., 1978; Jenkins et al., 1991; Choy et al., 1996). Cyrillo et al. (2001), estudando medidas corporais de animais da raça Nelore pertencentes à Estação Experimental de Zootecnia de Sertãozinho, obtiveram estimativas de herdabilidade iguais a 0,38 e 0,58 para altura na garupa, considerando-se modelo touro e modelo animal, respectivamente.

Na Tabela 4 estão apresentadas as correlações genéticas e fenotípicas entre todas as características estudadas. De modo geral, as correlações genéticas entre as características foram de moderadas a altas e positivas, indicando que características de crescimento são determinadas, em grande parte, pelos mesmos genes, com exceção de algumas correlações com a característica GDSf e o PN.

As correlações entre as características pré-desmama foram altas e positivas, com exceção do PN e GND, que foi igual a 0,22 . Knackfuss et al. (2006) encontraram correlações genéticas muito próximas para estas mesmas características, excetuando-se novamente a correlação entre o PN e GND, que foi igual a 0,41. Essas estimativas indicam que a seleção baseada em P210 e/ou P120 incidirá aumento do PN. Entretanto, como a correlação entre o PN e as características P120 e P210 são maiores se comparadas ao GND (no cálculo do GND o PN é excluído), uma forma de se evitar o aumento do PN nas futuras gerações é considerar os ganhos entre idades padrão, e não os pesos, como critérios de seleção.

As estimativas de correlações genéticas entre os pesos pré e pesos e alturas pós-desmama foram de moderadas a altas, indicando que a seleção para um dos pesos promoverá mudança genética nos outros pesos na mesma direção, com maior ou menor intensidade. Porém, o mesmo fato não foi observado entre os ganhos de peso pré e pós-demama, cujas correlações foram bem baixas. Como relatado anteriormente, o crescimento pré-desmama é sobretudo influência ambiental, tanto do ambiente permanente materno como do ambiente temporário, e somente após o desmame o ganho de peso está livre da influência materna. Portanto, para mudança genética nos ganhos das fases pré e pós-desmama, adota-se peso padronizado em que as duas fases estão somadas ou consideram-nos em um índice de seleção. Correlação genética baixa entre ganhos pré e pós-desmama foi relatada por Lôbo et al. (2000), em revisão de parâmetros genéticos de bovinos criados em regiões tropicais.

Quanto à característica utilizada como critério de seleção em machos (P378), as correlações genéticas estimadas com todas as outras foram altas e positivas, com exceção do GDSf, sugerindo que a seleção para esta característica promove resposta correlacionada nas demais. Knackfuss et al. (2006) reportaram correlações genéticas superiores às encontradas neste estudo (iguais a 1,0;0,92; 1,0 e 0,94 entre P378 e P550, G112, ALTm e ALTf, respectivamente), indicando que genes em comum influenciam essas características.

Correlações genéticas negativas foram observadas entre o GDSfe os P378, GDSm e o G112 e correlação genética bem inferior à unidade foi observada entre o P378 e P550, sugerindo a existência de interação genótipo $\times$ ambiente. O GDSf e as demais características em questão diferem por: serem medidos em apenas um único sexo (fêmeas ou em machos); os animais estarem em ambientes completamentes distintos (em regime de pastagem ou em confinamento, que possui controle ambiental mais rigoroso); e também por serem tomadas em fases diferentes de crescimento (do desmame ao sobreano e do desmame a um ano de idade). O fato de GDSf compreender um período consideravelmente maior e em regime de pastagem faz com que as fêmeas passem um período de estiagem logo após o desmame (março), que pode comprometer seu ganho de peso. De fato, na Tabela 1 , observa-se que o ganho médio diário é 2,80 vezes menor para as fêmeas em comparação aos machos. Resultados diferentes foram relatados por Mercadante et al. (2003) e

Tabela 4 - Estimativas das correlações genéticas (acima da diagonal) e fenotípicas (abaixo da diagonal) entre as características estudadas

Table 4 - Estimates of genetic correlation (above diagonal) and phenotypic (below diagonal) between the studied traits

\begin{tabular}{|c|c|c|c|c|c|c|c|c|c|c|c|}
\hline & $\mathrm{PN}$ & P 120 & P 210 & GND & P 378 & P 550 & GDSm & GDSf & G1 12 & ALTm & $\mathrm{ALTf}$ \\
\hline $\mathrm{PN}$ & - & 0,66 & 0,52 & 0,22 & 0,58 & 0,54 & 0,47 & 0,09 & 0,53 & 0,52 & 0,62 \\
\hline P 120 & 0,36 & - & 1,00 & 0,95 & 0,92 & 0,99 & 0,64 & 0,68 & 0,46 & 0,78 & 0,74 \\
\hline P 210 & 0,18 & 0,71 & - & 0,99 & 0,90 & 0,95 & 0,58 & 0,50 & 0,46 & 0,72 & 0,72 \\
\hline GND & 0,17 & 0,88 & 0,98 & - & 0,84 & 0,94 & 0,50 & 0,54 & 0,32 & 0,65 & 0,66 \\
\hline P 378 & 0,41 & 0,68 & 0,75 & 0,70 & - & 0,61 & 0,92 & $-0,10$ & 0,77 & 0,81 & 0,64 \\
\hline P 550 & 0,31 & 0,65 & 0,71 & 0,69 & 0,23 & - & 0,42 & 0,69 & 0,35 & 0,63 & 0,78 \\
\hline GDSm & 0,25 & 0,15 & 0,14 & 0,09 & 0,65 & 0,16 & - & $-0,25$ & 0,98 & 0,84 & 0,59 \\
\hline GDSf & 0,06 & $-0,11$ & $-0,17$ & $-0,19$ & $-0,02$ & 0,55 & $-0,05$ & - & $-0,27$ & 0,36 & 0,79 \\
\hline G112 & 0,28 & 0,18 & 0,18 & 0,13 & 0,74 & 0,11 & 0,85 & $-0,04$ & - & 0,70 & 0,57 \\
\hline $\mathrm{ALTm}$ & 0,39 & 0,55 & 0,61 & 0,56 & 0,70 & 0,30 & 0,47 & 0,09 & 0,42 & - & 0,94 \\
\hline $\mathrm{ALTf}$ & 0,36 & 0,56 & 0,57 & 0,52 & 0,26 & 0,72 & 0,24 & 0,30 & 0,20 & 0,50 & - \\
\hline
\end{tabular}


Knackfuss et al. (2006), cujos valores estimados de correlação genética entre P378 e P550, tomados nas mesmas condições ambientais em rebanhos Nelore e Gir, foram 0,88 e 1,0 . Esses resultados podem sugerir que, mesmo adaptados aos trópicos, os animais da raça Caracu sejam mais exigentes que os zebuínos e que o crescimento das fêmeas em pastagem após a desmama, durante a estiagem, seja governado não pelos genes para crescimento em um ambiente adequado às necessidades, mas sim por genes para crescimento em ambiente hostil. Contudo, estudos detalhados são necessários para comprovar este fato.

Foram observadas correlações genéticas de moderadas a altas e positivas entre os pesos e ganhos de peso com as alturas de machos e fêmeas, variando de 0,36 a 0,86 , sugerindo que genes que influenciam os pesos e ganhos nas diferentes idades exercem efeito também sobre medidas corporais. Knackfuss et al. (2006), estudando características de crescimento em um rebanho Gir também da Estação Experimental de Zootecnia de Sertãozinho, também encontraram correlações genéticas de moderadas a altas. Outros autores relataram que a altura na garupa é uma característica com correlação moderada e positiva com peso à desmama (Vargas et al., 2000), peso aos 378 dias de idade e outras medidas corporais (Cyrillo et al., 2001).

As correlações fenotípicas foram inferiores às genéticas para todas as características em estudo. Valores negativos de correlações fenotípicas foram observadas entre o GDSfe as demais características, com exceção do PN, P550 e as medidas corporais.

\section{Conclusões}

Os pesos obtidos durante o aleitamento são mais influenciados pelo ambiente materno que pelos genes do próprio animal para crescimento ou da mãe para habilidade materna.

Os valores das estimativas de herdabilidade encontradas para as características pós-desmama indicam que a seleção que tem como critério o desempenho do próprio indivíduo proporcionará progresso genético eficiente.

As estimativas de correlações genéticas indicam que a seleção para crescimento com base nos pesos pósdesmama têm grande influência nos pesos em diferentes idades, nos ganhos e nas medidas corporais.

\section{Literatura Citada}

ALBUQUERQUE, L.G.; MEYER, K. Estimates of direct and maternal genetic effects for weights from birth to 600 days of age in Nelore cattle. Journal of Animal Breeding and Genetic, v.118, p.83-92, 2001.
BOLDMAN, K.G.; KRIESE, L.A.; Van VLECK, L.D. et al. A manual for use for MTDFREML. A set of programs to obtain estimates of variances and covariances. Lincoln: Department of Agricultural; Agricultural Research Service, 1995. 129p.

BOURDON, R.M.; BRINKS, J.S. Scrotal circumference yearling Hereford bulls: Adjustment factors, heritabilities and genetics, environmental and phenotypic relationships with growth traits. Journal of Animal Science, v.62, p.958967, 1986.

CHOY, Y.H.; BRINKS, J. S.; BOURDON, R.M. Genetic evaluation of mature weight, hip height and body condition score in an Angus herd. Journal of Animal Science, v.74, p.107 (Abst.), 1996 (aupp1.).

CYRILLO, J.N.S.G.; RAZOOK, A.G.; FIGUEIREDO, L.A. et al. Estimativas de tendências e parâmetros genéticos do peso padronizado aos 378 dias de idade, medidas corporais e perímetro escrotal de machos Nelore de Sertãozinho, SP. Revista Brasileira de Zootecnia, v.30, p.56-65, 2001.

DOBSON, A.J. An introduction to generalized linear models. Melbourne: Chapman and Hall, 1990. 174p.

ELER, J.P.; FERRAZ, J.B.S.; DIAS, F. Estimação de parâmetros genéticos para características produtivas na raça Nelore, I Fase pré-desmama In: REUNIÓN DE LA ASSOCIACION LATINOAMERICANA DE PRODUCCIÓN ANIMAL, 17. 2001, La Habana. Proceedings... Havana: Associación Lationo-Americano de Producción Animal, 2001. 1 CD-ROM.

ELER, J.P.; Van VLECK, L.D.; FERRAZ, J.B.S. et al. Estimation of variance due to direct and maternal effects for growth traits of Nelore cattle. Journal of Animal Science, v.73, p.3253$3258,1995$.

EUCLIDES FILHO, K.; SILVA, M.A.; MILAGRES, J.C. Estimativas de parâmetros genéticos e fenotípicos de pesos e ganhos de peso durante o aleitamento. Revista Brasileira de Zootecnia, v.7, p.234-244, 1978.

FERREIRA, G.B.; MACNEIL, M.D.; Van VLECK, L.D. Variance components and breeding values for growth traits from different statistical models. Journal of Animal Science, v.77, p.26412650, 1999.

JENKINS, T.G.; KAPS, M.; CUNDIFF, L.V. et al. Evaluation of between and within breed variation in measures of weightage relationships. Journal of Animal Science, v.69, p.3118-3128, 1991 .

KARSBURG, J. H. Estimativas de parâmetros genéticos de características de carcaças medidas por ultra-sonografia e de desenvolvimento ponderal em bovinos da raça Santa Gertrudes. Pirassununga: Universidade de São Paulo, 2003. 96p. Dissertação (Mestrado em Qualidade e Produtividade Animal) - Universidade de São Paulo, 2003.

KNACKFUSS, F.B.; RAZOOK, A.G.; MERCADANTE, M.E.Z. et al. Seleção para peso pós-desmama em um rebanho Gir. 2. Estimativas de variâncias e parâmetros genéticos dos efeitos direto e materno para características de crescimento. Revista Brasileira de Zootecnia, v.35, n.3, p.726-732, 2006.

KOOTS, K.; GIBSON, J.; SMITH, C. et al. Analyses of published genetic parameters estimates for beef production traits. 1. Heritability. Animal Breeding Abstracts, v.62, p.309338,1994

KRIESE, L.A.; BERTRAND, J.K.; BENYSHEK, L.L. Age adjustment factors, heritabilities and genetic correlations for scrotal circumference and related growth traits in Hereford and Brangus bulls. Journal of Animal Science, v.69, p.478-489, 1991.

LÔBO, R.N.B.; MADALENA, F.E.; VIEIRA, A.R. Average estimates of genetic parameters for beef and dairy cattle in tropical regions. Animal Breeding Abstracts, v.68, p.433-462, 2000.

MARQUES, L.F.A.; PEREIRA, J.C.C.; OLIVEIRA, H.N. et al. Componentes de (co)Variância e parâmetros genéticos de características de crescimento da raça Simental na Brasil. Arquivo Brasileiro de Medicina Veterinária e Zootecnia, v. 51, p.363-370, 1999 . 
MASCIOLI, A.S.; ALENCAR, M.M.; BARBOSA, P.F. et al. Estimativas de parâmetros genéticos e proposição de critério de seleção para pesos na raça Canchim. Revista Brasileira de Zootecnia, v.25, p.72-82, 1996.

MASCIOLI, A.S.; PAZ, C.C.P.; EL FARO, L. et al. Estimativas de parâmetros genéticos e fenotípicos para características de crescimento até a desmama em bovinos da raça Canchim. Revista Brasileira de Zootecnia, v.26, p.709-713, 1997.

MELLO, S.P.; ALENCAR, M.M.; SILVA, L.O.C. et al. Estimativas de (co)variâncias e tendências genéticas para pesos em um rebanho Canchim. Revista Brasileira de Zootecnia, v.31, p.1707-1714, 2002.

MERCADANTE, M.E.Z.; FIGUEIREDO, L.A.; TROVO, J.B.F. et al. Estimativas de parâmetros e mudança genética em características de crescimento do rebanho Caracu de Sertãozinho. In: REUNIÃO ANUAL DA SOCIEDADE BRASILEIRA DE ZooteCniA, 35., 1998, Botucatu. Anais... Botucatu: Sociedade Brasileira de Zootecnia, 1998. p.380-382.

MERCADANTE, M.E.Z.; PACKER, I.U.; RAZOOK, A.G. et al. Direct and correlated responses to selection for yearling weight on reproductive performance of Nelore cows. Journal of Animal Science, v.81, p.376-384, 2003.

MERCADANTE, M.E.Z.; LÔBO, R.B.; BORJAS, A.R. Parámetros genéticos para características de crecimiento en cebuínos de carne. Archivos Latinoamericanos de Produccion Animal, v.3, p.45-89, 1995.

MEYER, K. Estimates of genetic parameters for weaning weight of beef cattle fitting a regression on maternal phenotype. Livestock Production Science, v.52, p.187-199, 1997.

NEVILlE JR., W.E.; SMITH, J.B.; MULLINIX, B.G. et al. Relationships between pelvic dimensions, between pelvic dimensions and hip height and estimates of heritabilities. Journal of Animal Science, v.47, p.1089-1094, 1978.

QUEIROZ, S.A.; PELICIONI, L.C.; SILVA, B.F. et al. Índices de seleção para um rebanho Caracu de duplo propósito. Revista Brasileira de Zootecnia, v.34, p.827-837, 2005.
RAZOOK, A.G.; FIGUEIREDO, L.A.; BONILHA NETO, L.M. et al. Selection for yearling weight in Nelore and Guzerá zebu breeds: selection applied and response in 15 years of progeny. In: WORLD CONGRESS ON GENETICS APPLIED TO LIVESTOCK PRODUCTION, 6., 1998, Armidale. Proceedings... Armidale: 1998. p. 133-136.

RAZOOK, A.G.; FIGUEIREDO, L.A.; BONILHA NETO, L.M. et al. Intensidades de seleção e respostas diretas e correlacionadas em 10 anos de progênies de bovinos da raça Nelore e Guzerá selecionados para peso pós-desmame. Boletim da Industria Animal, v.50, n.2, p.147-163, 1993.

RIBEIRO, P.M.T.; FERRAZ, J.B.S.; ELER, J.P. Parâmetros genéticos e nível de endogamia em bovinos da raça Santa Gertrudis no Brasil. Arquivo Brasileiro de Medicina Veterinária e Zootecnia, v.52, p.641-646, 2000.

STATISTICAL ANALYSIS SYSTEM - SAS. SAS/STAT. version 8 Cary: 2000 .

SCARPATI, M.T.V.; LÔBO, R.B. Modelos animais alternativos para estimação de componentes de (co)Variância e de parâmetros genéticos e fenotípicos do peso ao nascer na raça Nelore. Revista Brasileira de Zootecnia, v.28, p.512-518, 1999.

SIQUEIRA, R.L.P.G.; OLIVEIRA, J.A.; LÔBO, R.B. et al. Análise de variabilidade genética aditiva de característica de crescimento na raça Nelore. Revista Brasileira de Zootecnia, v.32, p.99-105, 2003

VARGAS, C.A.; ELZO, M.A.; CHASE, C.C. et al. Genetic parameters and relationship between hip height and weight in Brahman cattle. Journal of Animal Science, v.78, p.3045-3052, 2000. 